\title{
IMPROVING STREET RECONSTRUCTION PROJECTS IN CITY CENTERS THROUGH COLLABORATIVE PRACTICES
}

\author{
Olli Seppänen ${ }^{1}$, Rita Lavikka ${ }^{2}$, Joonas Lehtovaara ${ }^{3}$, and Antti Peltokorpi ${ }^{4}$
}

\begin{abstract}
Renovation and relocation of underground utilities and renovating the streets are essential to maintain urban infrastructure. In cities, street reconstruction projects cause substantial harm to citizens in the form of traffic jams, noise, and poor access to businesses. Although some harm is unavoidable, the harm could be mitigated, for example, by decreasing overall construction durations. We used design science research to diagnose the current state of street reconstruction projects in the City of Helsinki and to develop a new model aimed at shortening project durations. The diagnosis was made based on interviews, workshops, observations, a survey, and an archival study. The identified key root causes of problems were lack of collaboration and inflexible contract forms in projects with high uncertainty. The new model was co-created with stakeholders participating in these projects, including a collaborative development phase, a shared situation picture among actors, and joint risk analysis of all parties. The study's key contribution was the way to use design science research to start a lean implementation in a challenging project type with multiple public stakeholders. The City of Helsinki will pilot and further develop the model in three street reconstruction projects.
\end{abstract}

\section{KEYWORDS}

Street reconstruction, contract forms, collaboration, trust, design science research.

\section{INTRODUCTION}

Renovation and relocation of underground utilities, located under the streets, are essential for cities as infrastructures get older and need to be renewed. At the same time, traffic systems and roads are also typically renovated. Citizens and businesses suffer from several side effects of these street renovation projects, such as traffic jams and noise, as these projects are frequently delayed.

Although requirements for street renovation projects are often quite exact, a lot of uncertainty exists in underground conditions due to insufficient documentation of existing conditions, such as bedrock elevation or existing utilities. The projects also typically

Associate Professor, Department of Civil Engineering, Aalto University, Finland, olli.seppanen@aalto.fi, orcid.org/0000-0002-2008-5924

Senior Scientist, Technical Research Centre of Finland (VTT), Finland, rita.lavikka@vtt.fi, orcid.org/0000-0003-1200-4773

Doctoral Candidate, Department of Civil Engineering, Aalto University, Finland, joonas.lehtovaara@aalto.fi , orcid.org/0000-0002-4761-3811

4 Assistant Professor, Department of Civil Engineering, Aalto University, Finland, antti.peltokorpi@ aalto.fi, orcid.org/0000-0002-7939-6612 
involve multiple utility systems, such as streets, heating, water, electricity, and telecommunication networks, owned by different stakeholders, making the coordination and governance of such projects challenging (Vilventhan and Kalidindi 2018).

Typically, cities as public entities are bound by competition laws and tend to use traditional contract forms, such as design-bid-build (DBB) (Rizk and Fouad 2007), which have been shown to function poorly in an environment with uncertainty (e.g. Lahdenperä (2012). Early contractor involvement through partnering and competitive dialogue before the preferred bidder is chosen have been suggested as implementation strategies for large infrastructure projects (Opsahl et al. 2015; Wondimu et al. 2016). Collaborative contract forms are an attractive alternative but hard to implement in a public entity if the project is not financially big enough or if the renovated utilities are owned by multiple organisations. On the other hand, better coordination between local public authority and utility companies in the design process can prevent unexpected delays (Sturgill et al. 2014).

Because of the number of stakeholders involved, coordination of work is crucial. In lean construction, collaborative methods such as the Last Planner® System (LPS) (e.g. Ballard 2000) have been proposed to improve the coordination process and plan reliability. In addition to LPS, digital tools may be required to achieve a shared situation picture (Kärkkäinen et al. 2019). Increased transparency brought by lean and digital tools combined with more collaborative contract forms could lead to increased trust between stakeholders, contributing to innovations and reducing project buffers (Uusitalo et al. 2019), thereby decreasing project duration and the harm to citizens. Although good solutions have already been reported in other contexts, additional research based on a thorough diagnosis of the current state is required to develop a holistic solution that applies to the context of street renovation.

This paper aims to diagnose and construct a practical solution to street renovation projects to minimise delays and harm to citizens. Empirical research is conducted in the context of street renovation projects in the City of Helsinki. Helsinki's existing infrastructure requires renovation, and new streets are being built at an increasing pace due to the age of infrastructure and population growth. This infrastructure must stay functional during the renovation period and provide citizens with clean water, heating, cooling, electricity, and connectivity to the internet.

Currently, street works in Helsinki cause considerable harm to street users. The main problems of street projects are the excessively long durations of construction work and the significant direct and indirect disadvantages they cause in their area of influence. Work causes disruption while congesting key traffic routes to the detriment of street residents, businesses, and other users. The disruptions cause financial losses for various stakeholders. Construction sites and traffic arrangements pose safety risks to street users. Site areas often have inadequate service levels for road users, e.g., inadequate signage and uneven pavements. The city started a major development effort which included this research study and several other practical initiatives related to, e.g., communication with stakeholders and applications for citizens to provide real-time feedback.

One of this research's practical aims is to reduce street projects' disadvantages during construction. For this reason, the study explores the current way of conducting and managing street renovation projects and developing operations comprehensively. The design phase has been covered to the extent that the on-site turnaround times are concerned. Improvement of the design process itself is not the subject of research. The study will apply lean thinking as it has been successful in improving construction flow. 
For example, a case study conducted by Kung et al. (2008) showed that water and sewer service installations' productivity was improved through lean principles. Currently, lean thinking or digital tools are not widely adopted in street renovation projects.

The study aims to answer two questions: 1) What are the root causes of long durations of street reconstruction projects? and 2) How to implement lean and digital tools to develop these projects? The paper is structured as follows. After presenting the methodology, a diagnosis of the current state of the road renovation projects is presented. Then, the proposed solution is formed. Finally, the results are discussed, conclusions are made, and suggestions for future research initiatives are provided.

\section{METHODOLOGY}

The study was executed as a design science research (DSR), a research method aiming to solve a practical problem (Baskerville et al. 2018). DSR forms an iterative process where the solution is created in tight collaboration with researchers and practitioners, suiting exceptionally well for the study's aim (Holmström et al. 2009). As a practical problem to be solved, we investigated the street reconstruction projects in the City of Helsinki centre.

In this study, DSR is formed around three steps: i) diagnosis of the problem, ii) formulation of a solution and iii) discussion of the study's contribution and further action steps. First, we diagnosed the problem with semi-structured interviews of representatives from all major stakeholders (the City of Helsinki, utility companies, contractors, designers). Then, we organised a workshop to get a common understanding of issues. After that, we conducted observations on four on-going projects and implemented a survey of existing communication practices on one construction project. Finally, we conducted an archival study of documentation related to three completed projects. Table 1 shows the data used for diagnosis.

Table 1: Data sources for diagnosis

\begin{tabular}{ccc}
\hline Data type & $\begin{array}{c}\text { Data collection } \\
\text { period }\end{array}$ & Analysed materials \\
\hline Interviews & $2 / 2019-6 / 2019$ & $\begin{array}{c}55 \text { interview sessions with 75 participants (15 City of } \\
\text { Helsinki, 23 contractors, 10 designers, 20 utilities, } \\
7 \text { others) }\end{array}$ \\
$\begin{array}{c}\text { Document } \\
\text { analysis } \\
\text { Site }\end{array}$ & $\begin{array}{c}\text { Three projects } \text { - contracts, schedules and their } \\
\text { updates, meeting minutes, site diary }\end{array}$ \\
$\begin{array}{c}\text { Observations } \\
\text { Survey }\end{array}$ & $\begin{array}{c}11 / 2018-12 / 2018 \\
\text { and 5/2019-6/2019 } \\
\text { Observations in four projects: situation picture, } \\
\text { Workshop }\end{array}$ & $\begin{array}{c}\text { collaboration and trust, problems and their solutions } \\
\text { Survey related to communication in projects, } \\
\text { conducted in one project, 29 respondents } \\
\text { 33 participants (6 City of Helsinki, 6 contractors, } \\
4 \text { designers, 9 utilities, 7 others) }\end{array}$ \\
\hline
\end{tabular}

The semi-structured interviews were used to get an initial diagnosis of the current state and challenges and potential development ideas. Interviews were recorded and transcribed verbatim by using a transcription service. The interview questions for different stakeholder groups varied and focused on issues of interest to that stakeholder group. All interviewees were asked about the current process, challenges and best practices in different stages of the process. Data analysis was based on qualitative content analysis, where extracts were coded to themes first for each stakeholder type and then 
further by problem type. In classification, root cause analysis was used to understand what happened and why. Because different stakeholder groups had a very different understanding of root causes of problems, observation and document analysis were used to validate the found root causes in a real context. The same themes as in interviews were used to classify these observations.

Next, we organised two workshops to help define a solution. As starting information for workshops, we presented the findings from the diagnosis phase. The first workshop focused on improving collaboration and problem-solving in projects, and the second workshop on improving situational awareness in projects. Based on these workshops and our diagnosis, we developed a proposed new model in collaboration with the city. The model was validated in a final workshop with all stakeholders, and modifications were made based on stakeholder feedback.

\section{DIAGNOSIS}

An interesting result from the interview study was the wide disagreement between stakeholder groups regarding the root causes of street renovation projects' delays. This lack of common understanding was verified with the survey, site observations, and the diagnosis workshop. Due to space limitations, we present the views of each key stakeholder type separately, then briefly describe the results of observations and document analysis and finally present our synthesis of results.

Contractors tended to emphasise the imbalanced distribution of risks to project parties and the inability to participate enough in the design phase. Their challenge was the obligation to coordinate work without all parties' commitment, especially the utility companies. The designs could not be followed due to continuous surprises in subsurface conditions. The fixed-price contract forces the contractor to maximise the utilisation rate of expensive equipment, increasing the harm caused to citizens because new areas need to be excavated when work stops in another area due to an open problem. The bottleneck identified by all contractors was the speed of decision-making by the city. According to the contract, the contractor should never proceed with change order work before written confirmation. Still, they had to start several changes at their own risk to maximise resource utilisation and prevent disputes in practice.

The representatives of the city had a very different view of the root causes. Their perception was that contractors did not plan their work adequately and did not update the plans when changes occurred. The city could not accept change order requests timely because the contractors failed to provide enough detailed justification, requiring multiple iterations of each change request. Rather than being proactive and proposing solutions, contractors sent information of deviations and stood by waiting for a response.

For various utility companies (teleoperators, district heating, water, tram lines, etc.), the key challenge was operating in a multi-project environment. Each company's scope related to one project is quite small, so it does not make sense to sit through each 3-hour meeting. Information about projects starting comes too late and inconsistently from different people or organisations. The designs are not coordinated well enough between the various owners of infrastructure below the street. There is no transparency to project schedules. Much of the time, the work is delayed from the schedule and then urgently required, but the utility companies need to plan their resources over hundreds of projects.

The key problems from the designers' point of view were the last-minute change requests in design and in getting starting information for design from various project stakeholders. Especially soil information and information of the location of existing 
utilities is inadequate when designing the project. Latitude and longitude coordinates are known for many systems but not the elevation. The amount of money spent on investigations of current conditions was deemed inadequate.

The analysis of observations and documentary evidence confirmed that there is a lack of collaboration in the projects. The schedules and planning had shortcomings and were not updated regularly by contractors. All analysed projects started degenerating into a dispute after the first time extension request by the contractor. At this point, the documents, meeting minutes, and observed meetings started to turn increasingly hostile. Change order requests were open for months, and clarifications were asked related to most change orders. There were many change orders - during the excavation phase, the projects had unexpected problems on $19 \%$ (project 1) to 66\% (project 3) of days during periods when excavation was being done. All these problems started a change order process that often took months to resolve.

However, one of the observed projects (project 4) was different even though it had a similar contract as the other analysed projects. The contractor and client had managed to achieve a good and collaborative approach. The contractor was proactive and proposed a solution for each issue. The Owner was ready to decide whether to proceed with the contractor's solution immediately. Designers were sent as-built measurement information after implementation, and they updated the designs. All paperwork was completed later and the change order hours were booked and invoiced. The contractor was operating at its own risk without following the change order process specified in the contract. Although the project had delays during construction, the project was the only investigated project that finished on time.

Based on data analysis, the root causes of delays were identified and validated in the workshop. At this point, we were able to achieve enough common understanding of root causes to start working on the solution, although the parties' opinions were still quite far from each other. Table 2 shows a summary of identified root causes.

\section{DEVELOPING THE SOLUTION}

The initial solution ideas were collected during interviews and discussed during the first diagnosis workshop. Two additional workshops were organised during the development of the solution. Workshop 2 focused on improving collaboration and changing the contracts. Workshop 3 focused on collaborative planning and situational awareness. All workshops included participants related to all main stakeholder groups. Workshops were conducted using facilitated small group discussions with researchers taking detailed notes in each small group. Table 3 summarises the main results of the workshops.

Based on these workshop findings, two meetings were organised between the researchers and the City of Helsinki. The workshop results were discussed in the meetings, and a new model was developed based on workshop results. All recommendations could not be implemented in the new model due to legal constraints on public entities or lack of willingness, but the resulting model included changes for all stages of the process. In addition to stages that were traditionally part of the process, a new development stage was added before the construction phase.

In the design phase, the key changes were in the change of city departments' role, additional soil investigations, and the definition of risks and uncertainties. The design phase requires more participation from the city organisation responsible for overseeing the construction phase to evaluate constructability. Risks and uncertainties should be 
defined already in the design phase and used to inform additional soil studies. The number of test excavations and soil studies will be increased substantially.

In preparation for construction, the key changes relate to the way the main contractor is selected. The call for bids will include constraints on scheduling and the risk analysis performed in the design phase. Public procurement requires a price component, but the focus will shift to evaluating the contractor's planning expertise, bringing new ideas in the development phase, plans to decrease harms on citizens, and the ability to recognise risks and opportunities. The goal is to find a collaborative partner for the development phase.

Table 2: Root causes of delays as proposed and validated in the workshop

\begin{tabular}{|c|c|}
\hline Root causes of long durations & Description \\
\hline Contract form & $\begin{array}{l}\text { In most projects, Design-Bid-Build is used as the contract } \\
\text { form. The contract form does not create prerequisites for } \\
\text { flexible implementation of projects without considerable } \\
\text { risk to the contractor }\end{array}$ \\
\hline Continuous deviations & $\begin{array}{l}\text { Deviations from design impact duration because work } \\
\text { cannot proceed before the deviation has been resolved. } \\
\text { Most common deviation categories: 1) surprising soil } \\
\text { conditions 2) missing information about utilities and } \\
\text { 3) surprising underground structures }\end{array}$ \\
\hline $\begin{array}{l}\text { Reacting to deviations and } \\
\text { change management }\end{array}$ & $\begin{array}{c}\text { Change orders require written approval from the city } \\
\text { before implementation, including work method and } \\
\text { possible cost and schedule impacts. In practice, the } \\
\text { written approval is not received timely but requires a } \\
\text { lengthy process. Work often proceeds at the risk of the } \\
\text { contractor. Time and attention of management are used } \\
\text { on paperwork. }\end{array}$ \\
\hline Collaboration and trust & $\begin{array}{c}\text { The collaborative and trustful atmosphere is possible to } \\
\text { achieve and has led to good outcomes (e.g. project 4). } \\
\text { However, in general current contract form does not create } \\
\text { good preconditions for trust. Instead of collaborative } \\
\text { problem solving, the current model leads to documenting } \\
\text { problems and communicating with the other party through } \\
\text { claims and formal letters. }\end{array}$ \\
\hline $\begin{array}{c}\text { Challenges related to schedules } \\
\text { and logistics }\end{array}$ & $\begin{array}{l}\text { Good planning of work is important for avoiding delays. } \\
\text { The current process does not allow enough time for } \\
\text { planning and rather emphasises quick start of work. Most } \\
\text { contractors do not have adequate planning skills or } \\
\text { resources. Schedules should be updated flexibly during } \\
\text { the project to give each party an up-to-date view of what } \\
\text { is expected }\end{array}$ \\
\hline Situational awareness & $\begin{array}{l}\text { There is a lack of situational awareness for all } \\
\text { stakeholders who are not full time on site. Real-time } \\
\text { situational awareness is important for all parties to ensure } \\
\text { schedule updates when deviations happen. }\end{array}$ \\
\hline
\end{tabular}

In the new model, which is illustrated in Figure 1, the development phase has a critical role. In the development phase, the project's rules are defined, and answers to open questions are collaboratively developed. Collaborative planning using the Last Planner ${ }^{\circledR}$ System is performed. The end result of the development phase includes a common risk analysis and risk management plan. Each identified risk includes an allowance in money 
and time. Risks can be controlled by additional investigations in uncertain areas to confirm design assumptions. Additionally, the systems for real-time situation picture are defined.

In the construction phase, decision-making is made considerably faster by predefined risks and decision paths. Decision-making is moved closer to the site enabling the Owner's supervisor to make immediate decisions. Changes related to recognised risks can be immediately resolved without requiring a change order process. In addition, schedules are continuously updated based on the process agreed in the development phase. The head contractor procures required IT systems to allow transparency. Transparency to construction operations allows much quicker handling of change requests from the site. Any schedule changes and costs can be validated based on the situation picture. Technologies include, for example, web-based scheduling systems, machine control systems, drones, and fixed cameras.

The model was validated in a workshop (13.11.2019) with 44 participants. Collaboration and trust were emphasised, and the need for an external lean consultant to facilitate the development phase's first implementations. Utility companies emphasised the need for effective, facilitated meetings. The participants emphasised that although the design phase already develops quite detailed designs (based on available information). Getting a shared understanding of constructability and mitigating risk with further studies should decrease the cycle times of projects significantly. Harm can also be decreased in other ways, such as innovations related to temporary traffic control measures. Based on the positive feedback from the workshop, the City of Helsinki decided to start pilot implementations in three projects.

\section{DISCUSSION}

Developing an improved process for street reconstruction projects proved to be extremely challenging due to a high number of stakeholders involved in relatively small projects. All stakeholders had different views of root causes of long durations of street projects, typically focusing on issues with other stakeholders. Achieving a common understanding of root causes was a lengthy process and required extensive evidence from various sources such as interviews, observations, a survey, and an archival study and debate in co-creative workshops. As the result of the diagnosis, a common understanding of key issues was achieved.

Design-Bid-Build contract type is not suitable for a project type with continuous needs for changes due to uncertain starting data. Flexibility, collaboration, and trust are required to cope with uncertainty and Design-Bid-Build tends to lead to opportunistic behaviour, lack of trust and can even prevent collaboration (Kortenko et al. 2020). Indeed, the only observed project that achieved collaboration and on-time delivery did so at an increased contractual risk to the contractor. While these findings are quite expected for any researcher in the lean domain, they need to be shown to apply in each separate context if a real impact is sought. Convincing a public entity to change their procurement practices that have been used for decades is not an easy task (e.g. Love et al. 2008) and may require this kind of extensive evidence collection. 
Table 3: Participants and key results of workshops

\begin{tabular}{ll}
\hline Workshop & \multicolumn{1}{c}{$\begin{array}{c}\text { Partici- } \\
\text { pants }\end{array}$} \\
\hline Workshop & Contractors \\
1 & $: 6$ \\
$(20.5 .2019)$ & Designers: \\
Common & 4 \\
under- & Utilities: 9 \\
standing of \\
challenges & City: 6 \\
& Others: 7 \\
& \\
& \\
& \\
& \\
Workshop & Contractors \\
2 & $: 5$ \\
(24.9.2019) & Designers: \\
Contract & 6 \\
forms and & Utilities: 10 \\
improving & City: 7 \\
collabora- & Others: 10 \\
tion &
\end{tabular}

\section{Main results}

1. Developing collaboration between stakeholders: Implementing a development phase before construction: collaborative scheduling, identifying of decision paths, change management rules. Common risk analysis and predefined ways to handle risks. Common incentives for commitment to project objectives.

2. Surprises and reacting to them: More soil investigations needed during preparation. Decision making closer to site. More use of BIM models in the process. Time and money contingencies to allow flexible change process.

3. Real-time situation picture: All parties agreed that transparency and development of situation picture is beneficial but requires trust.

1. Changes related to designers: Life cycle thinking to projects. Change of approach to emphasise constructability rather than just end product. Increasing prefabrication of elements. Detailed reviews of designs in collaboration with contractors in development phase.

2. Changes related to contractors: Alliance / IPD is too heavy contract form for most street projects. Potentially use DesignBuild with collaborative development phase as a template.

3. Changes related to utilities' owners: Better real-time communication of schedule changes. Design coordination requires more time and active collaboration

4. Measurement and evaluation of harm: Citizen body for the continuous evaluation of harms caused by contractors and which harm is acceptable. Continuous measurement of harm and solutions.

Workshop Contractors 3 (21.10. 2019) Real- Designers. time 4 situation picture, production planning and control
Utilities: 9

City: 8

Others: 10
1. Improved starting data. Classification of uncertainty related to design. Checklists for design to control uncertainty. Documenting assumptions and uncertain areas and reviewing them with the contractor and using methods which do not require excavation to evaluate current conditions. Use of drone measurements to get measurements of actual data after excavation.

2. Real-time situation picture and BIM models: All stakeholders should be trained in using BIM models and providing information for situation picture during the development phase. Incentives for transparency and collaboration. No punishments for sharing data.

3. Collaborative production planning and control: Collaborative production planning using the Last Planner ${ }^{\circledR}$ System, continuously rolling look-ahead schedule for the next six weeks. All stakeholders should participate, and all should have tasks in the schedule.

4. Internal communication: Development required on communication methods used: emphasise user interface and speed. Clear duration targets for decisions and RFIs. Continuous measurement of the decision process. 


\begin{tabular}{|c|c|c|c|}
\hline Design & $\begin{array}{l}\text { Preparation of } \\
\text { Construction }\end{array}$ & Development phase & Construction \\
\hline $\begin{array}{l}\text { Participants: All entities managing } \\
\text { design (City + utilities), design } \\
\text { consultants, construction managers } \\
\text { participate in the final phase of } \\
\text { design } \\
\text { Objective / changes } \\
\text { - Construction managers (City + } \\
\text { utilities) participate in evaluating } \\
\text { constructability already in design } \\
\text { phase } \\
\text { New tasks } \\
\text { - Defining risks and uncertainties } \\
\text { already in design phase } \\
\text { (collaboration of design } \\
\text { managers and construction } \\
\text { managers) } \\
\text { - More soil investigations } \\
\text { (including test excavations) } \\
\text { already in design phase in risky } \\
\text { areas }\end{array}$ & $\begin{array}{l}\text { Participants: All construction managers } \\
\text { Objective } \\
\text { - Selecting contractor with criteria which } \\
\text { enables getting the right partner for } \\
\text { development phase } \\
\text { Knowledge requirements of main } \\
\text { contractor } \\
\text { - Planning skills } \\
\text { - Ability to recognize risks and } \\
\text { opportunities } \\
\text { - Ability to propose alternative solutions } \\
\text { - Ability to minimize the harm of } \\
\text { construction to environment } \\
\text { Tasks } \\
\text { - Deciding the selection criteria of main } \\
\text { contractor } \\
\text { - Price component (lump sum / unit } \\
\text { price) } \\
\text { Quality component (evaluation of } \\
\text { skills e.g. by scoring the project } \\
\text { plan in addition to customary } \\
\text { references) } \\
\text { - In call for tenders, constraints for } \\
\text { planning and the risk analysis } \\
\text { created in design phase should be } \\
\text { appended }\end{array}$ & $\begin{array}{l}\text { Participants: All design managers, } \\
\text { construction managers, designers, } \\
\text { main contractor, other contractors } \\
\text { Objective: } \\
\text { - Preparation for construction phase } \\
\text { so that both the duration and extent } \\
\text { of harm to third parties can be } \\
\text { minimized. } \\
\text { Tasks } \\
\text { - Collaborative planning of work and } \\
\text { commitment to work plan } \\
\text { - Common risk analysis, pricing of } \\
\text { risks and risk management plan } \\
\text { - Defining metrics for success and } \\
\text { conditions of satisfaction } \\
\text { - Additional investigations of starting } \\
\text { data in risky locations. } \\
\text { - Planning temporary traffic } \\
\text { arrangements } \\
\text { - Alternative solutions and } \\
\text { innovations } \\
\text { - Decision making paths and times for } \\
\text { different types of deviations in } \\
\text { construction phase } \\
\text { - Defining requirements for situation } \\
\text { picture } \\
\text { - Target price and bonus scheme for } \\
\text { construction phase }\end{array}$ & $\begin{array}{l}\text { Participants: All construction } \\
\text { managers, main contractor, other } \\
\text { contractors. When changes occur, also } \\
\text { design managers and design } \\
\text { consultants. } \\
\text { Objective } \\
\text { - All actors have a real-time shared } \\
\text { situation picture } \\
\text { - Flexible process when deviations } \\
\text { occur by utilizing the risk analysis of } \\
\text { development phase } \\
\text { Tasks } \\
\text { - Continuous updates of schedule } \\
\text { - Real time situation picture for all } \\
\text { stakeholders (main contractor } \\
\text { procures the required systems). } \\
\text { - Quick decisions when there are } \\
\text { deviations in cases when the } \\
\text { deviation is related to a previously } \\
\text { recognized risk. }\end{array}$ \\
\hline
\end{tabular}

Figure 1: The new model based on the workshops

The proposed process itself also has limited novelty for a lean researcher or practitioner. The solution includes familiar pieces such as a development phase, use of the Last Planner® System for collaborative planning, increased prefabrication, and developing a shared understanding of risks. The key learnings of interest to lean practitioners are more related to the journey than the destination. Research-driven process change should generalise to other contexts where the Owners are reluctant to change their ways.

The research achieved its objective. Stakeholders were able to agree on root causes and a new way to procure and implement street reconstruction projects. The city has started using the new model in three new street reconstruction projects. The procurement in these projects has been based on a target price, including a development phase. The projects are currently on the way. Two of the three projects have reported good results from the development phase, but one has reported major challenges in collaboration. These differences will be investigated in future research.

\section{CONCLUSIONS}

The root causes of long durations of street reconstruction projects (RQ1) are linked to high uncertainty related to soil conditions, existing structures, and locations of utilities. The Design-Bid-Build contract form is too inflexible to deal with continuous changes caused by inadequate starting data for design. The work of various contractors needs to be better coordinated. A common understanding of the decision-making process and key risks is required in order to react faster when risks occur.

The stakeholders were able to agree on a new model for street reconstruction. The developed model is the answer to the second research question (RQ2). The model includes several lean elements, such as a collaborative development phase with joint risk analysis, movement away from Design-Bid-Build to target price with a bonus pool associated with project objectives, collaborative planning using Last Planner® System, and digital situational awareness for all parties. The study's key contribution is not the 
model itself but the way of using Design Science Research to achieve a common understanding of root causes and kick off a lean implementation in a challenging environment.

\section{ACKNOWLEDGMENTS}

The research project "Functional street projects" was supported financially and technically by the City of Helsinki, whose support is greatly appreciated. Any opinions, findings, conclusions, or recommendations expressed in this report are those of the authors and do not necessarily reflect the views of the City of Helsinki. The authors would like to thank the people participating in the interviews and workshops for the time invested and knowledge shared.

\section{REFERENCES}

Ballard, H.G., 2000. The last planner system of production control. Thesis (PhD). The University of Birmingham.

Kortenko, S. , Koskela, L. , Tzortzopoulos, P. and Haghsheno, S. (2020) Negative Effects of Design-Bid-Build Procurement on Construction Projects. In: Proc. 28th Annual Conference of the International Group for Lean Construction. Berkeley, California, USA, 6-10 Jul 2020. pp 733-744.

Kärkkäinen, R., Lavikka, R., Seppänen, O. and Peltokorpi, A. (2019). Situation Picture Through Construction Information Management, in: 10th Nord. Conf. Constr. Econ. Organ., pp. 155-161.

Lahdenperä, P. (2012) Making sense of the multi-party contractual arrangements of project partnering, project alliancing and integrated project delivery. Construction Management and Economics, vol. 30, no 1, pp. 57-79.

Love, P.E.D., Davis, P.R., Edwards, D.J. and Baccarini, D. (2008) Uncertainty avoidance: public sector clients and procurement selection. International Journal of Public Sector Management, Vol. 21 No. 7, pp. 753-776. doi.org/10.1108/09513550810904550.

Opsahl, H., Torp, O., Lædre, O., Andersend, B. and Olsson, N. (2015) Implementation Strategies in Large Infrastructure Projects. In: Proc. 23rd Ann. Conf. of the Int'l. Group for Lean Construction. Perth, Western Australia, July 29-31, pp. 319-328.

Rizk, T. and Fouad, N. (2007) Alternative Project Delivery Systems for Public Transportation Projects. International Journal of Construction Education and Research. 3(1), pp. 51-65.

Sturgill, R., Taylor, T.R.B., Ghorashinezhad, S. and Zhang, J. (2014) Methods to Expedite and Streamline Utility Relocations for Road Projects. Kentucky Transportation Center. Research Report KTC-14-15/SPR460-13-1F. Available at: Methods to Expedite and Streamline Utility Relocations for Road Projects (uky.edu).

Uusitalo, P., Seppänen, O., Peltokorpi, A., and Olivieri, H. (2019). Solving design management problems using lean design management: the role of trust. Engineering, construction and architectural management. 26 (7), 1387-1405.

Vilventhan, A. and Kalidindi, S.N. (2018) Utility relocation management in highway projects. Built Environment Project and Asset Management 8 (2), pp. 171-182.

Wondimu, P.A., Hosseini, A., Lohne, J., Hailemichael, E., and Lædre, O. (2016) Early Contractor Involvement in Public Infrastructure Projects. In: Proc. 24th Ann. Conf. of the Int'l. Group for Lean Construction, Boston, MA, USA, pp. 13-22. 